\title{
Review Article \\ Mechanisms of Neuroprotection by Quercetin: Counteracting Oxidative Stress and More
}

\author{
Lucio G. Costa, ${ }^{1,2}$ Jacqueline M. Garrick, ${ }^{1}$ Pamela J. Roquè, ${ }^{1}$ and Claudia Pellacani ${ }^{2}$ \\ ${ }^{1}$ Department of Environmental and Occupational Health Sciences, University of Washington, Seattle, WA 98105, USA \\ ${ }^{2}$ Department of Neuroscience, University of Parma Medical School, 43100 Parma, Italy \\ Correspondence should be addressed to Lucio G. Costa; lgcosta@u.washington.edu
}

Received 27 November 2015; Revised 4 January 2016; Accepted 6 January 2016

Academic Editor: Felipe Dal Pizzol

Copyright (c) 2016 Lucio G. Costa et al. This is an open access article distributed under the Creative Commons Attribution License, which permits unrestricted use, distribution, and reproduction in any medium, provided the original work is properly cited.

\begin{abstract}
Increasing interest has recently focused on determining whether several natural compounds, collectively referred to as nutraceuticals, may exert neuroprotective actions in the developing, adult, and aging nervous system. Quercetin, a polyphenol widely present in nature, has received the most attention in this regard. Several studies in vitro, in experimental animals and in humans, have provided supportive evidence for neuroprotective effects of quercetin, either against neurotoxic chemicals or in various models of neuronal injury and neurodegenerative diseases. The exact mechanisms of such protective effects remain elusive, though many hypotheses have been formulated. In addition to a possible direct antioxidant effect, quercetin may also act by stimulating cellular defenses against oxidative stress. Two such pathways include the induction of Nrf2-ARE and induction of the antioxidant/anti-inflammatory enzyme paraoxonase 2 (PON2). In addition, quercetin has been shown to activate sirtuins (SIRT1), to induce autophagy, and to act as a phytoestrogen, all mechanisms by which quercetin may provide its neuroprotection.
\end{abstract}

\section{Introduction}

Quercetin $\left(3,3^{\prime}, 4^{\prime}, 5,7\right.$-pentahydroxyflavone) is a common flavonol found in many fruits and vegetables such as apples, berries, onions, and capers [1]. Together with flavones, anthocyanidins, and various other compounds, flavonols belong to the class of flavonoids, which in turn represent a major class of polyphenols [2]. The dietary intake of all flavonoids has been estimated at about 200-350 mg/day, while intake of flavonols is about $20 \mathrm{mg} /$ day, of which quercetin accounts for nearly $50 \%$, with a daily intake of approximately $10 \mathrm{mg} /$ day [3]. A recent study carried out in Japan supported these estimates, as daily intake of quercetin was determined to be $16 \mathrm{mg}$ [4]. As quercetin is present in fruits and vegetables, high consumption of such foods can increase intake to over $200 \mathrm{mg} /$ day. Among vegetables, the highest levels of quercetin have been found in onions (Allium cepa L.), asparagus (Asparagus officinalis L.), and red leaf lettuce (Lactuca sativa L.), with lower levels in broccoli, green peppers, peas, and tomatoes. Apples are the fruits with the highest quercetin content, together with cherries and various berries (Table 1).
The quercetin in foods is not present as aglycone (i.e., without sugar groups), but as quercetin glycosides [3]. Quercetin aglycone is also sold as a dietary supplement, with a recommended dosage of $1 \mathrm{~g} /$ day [5].

\section{Quercetin: Absorption, Metabolism, and Bioavailability}

Quercetin glycosides present in foods (e.g., onions), such as quercetin glucoside, quercetin galactoside, or quercetin arabinoside, are deglycosylated to quercetin aglycone prior to passive absorption in the small intestine [6]. Enzymes involved in this first reaction are lactase phlorizin hydrolase (a beta-glucosidase) and/or gut microbiota-derived betaglucosidase, depending on the nature of the glycoside $[2,6]$. The quercetin aglycone undergoes significant and extensive biotransformation reactions to form glucuronidated, sulfated, and methylated metabolites, indicating an involvement of the phase II enzymes UGT (uridine $5^{\prime}$-diphosphoglucuronosyltransferase), SULT (sulfotransferase), and COMT (catechol-O-methyltransferase). Figure 1 illustrates 


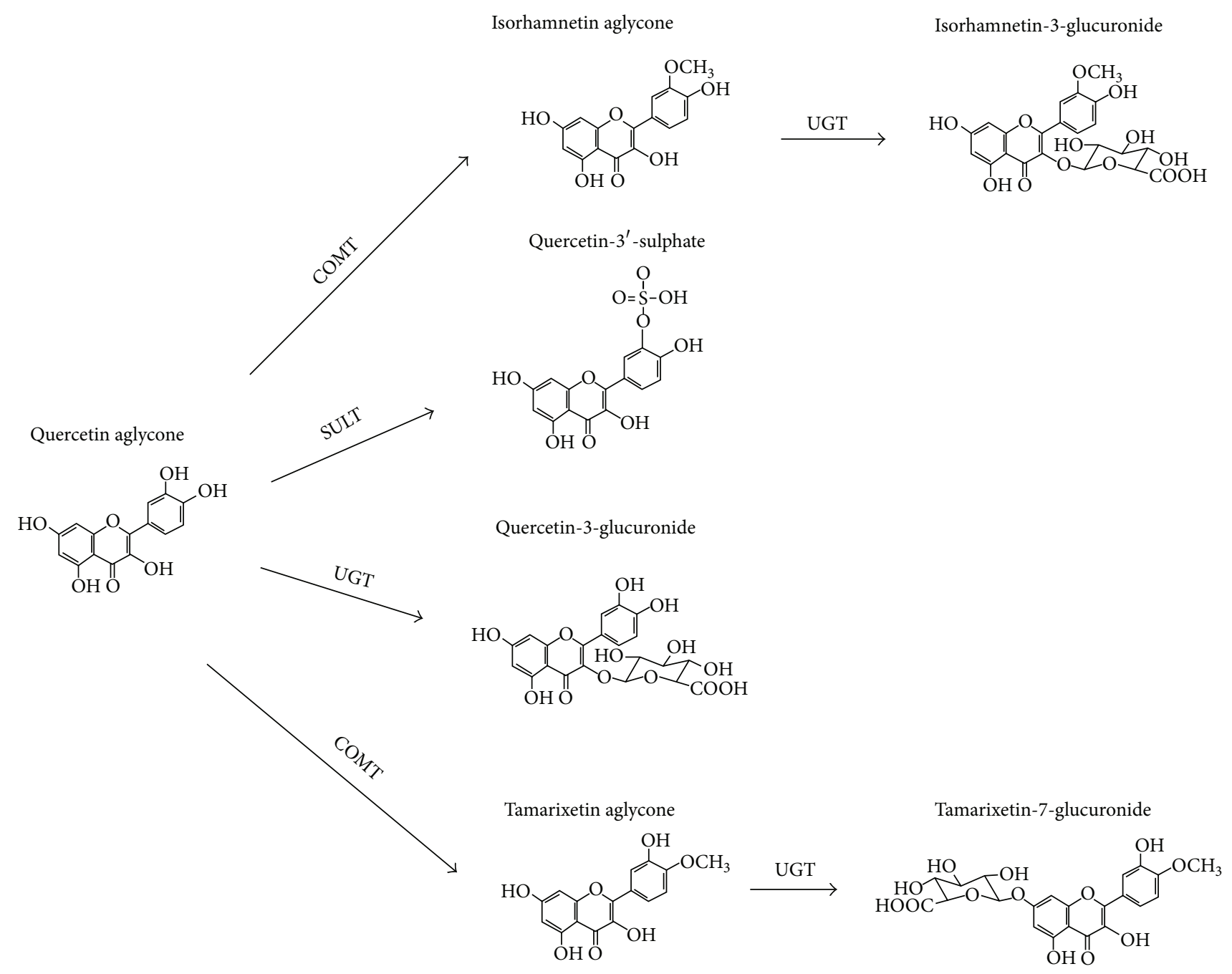

FIGURE 1: Structure of quercetin and of some of its principal metabolites (see text for further details).

TABLE 1: Quercetin content in selected vegetables and fruits $(\mathrm{mg} / 100 \mathrm{~g})$.

\begin{tabular}{lc}
\hline Onion & $11-33$ \\
Lettuce (red) & $10-30$ \\
Pepper & $10-30$ \\
Broccoli & $3-5$ \\
Tomato & $2-4$ \\
Asparagus & $7-20$ \\
Peas & 14 \\
\hline Apple & $2-5$ \\
Cherry & $1-3$ \\
Blueberry & 5 \\
\hline
\end{tabular}

Adapted from $[1,4,6]$.

examples of quercetin metabolites [ $3^{\prime}$-O-methyl-quercetin (isorhamnetin), quercetin-3-O-glucuronide, $3^{\prime}$-O-meth-
ylquercetin-O-glucuronide, and quercetin- $3^{\prime}$-O-sulfate] derived from these biotransformation reactions.

Studies in rats and pigs have shown that quercetin distributes to several tissues, particularly lung, kidney, colon, and liver, with lower levels in brain [7]. Total quercetin derived from the diet is normally present in plasma in the nanomolar range $(<100 \mathrm{nM})$ but can be increased to the low micromolar range after supplementation of quercetin aglycone or glycosides $[8,9]$. The half-life of quercetin ranges between 11 and $28 \mathrm{~h}$, suggesting the possibility of significantly increasing plasma concentration upon supplementation [8, 10]. In general, bioavailability of quercetin is low, and it varies significantly among individuals, though the underlying mechanisms are poorly understood [6].

Only limited amounts of quercetin aglycone are found after ingestion of quercetin, though there is some controversy on this issue (see, e.g., [11, 12]), and methylated, sulfated, and glucuronide metabolites are the most prominent moieties found in plasma. Studies have shown that glucuronidated metabolites have antioxidant abilities in vitro and in vivo 
$[13,14]$. Additional biological effects of methylated and sulfate metabolites have been reported [15-17], though some studies have failed to observe an effect of quercetin metabolites [18]. Of interest is also the observation that conjugated quercetin can enter the cell (erythrocyte), where it is converted to its nonconjugated form [19].

An important issue for the potential use of quercetin in vivo is whether it passes the blood-brain barrier (BBB) and what concentrations of quercetin and/or its metabolites are present in brain tissue. In vitro studies with $\mathrm{BBB}$ models consistently indicate that quercetin enters the brain [2022]. Upon administration of quercetin in vivo to rats and pigs, low levels (from picomolar to nanomolar) are found in brain tissue $[7,21,23]$. Of interest in this regard are the recent successful efforts to increase bioavailability of quercetin [24]. In particular, the formulation of quercetin in lipid nanoparticles significantly increases its penetration into the brain $[25,26]$. Additionally, coadministration of quercetin and alpha-tocopherol has been shown to increase the transport of quercetin across the blood-brain barrier [27].

Quercetin has an unremarkable toxicological profile, as evidenced by animal and human studies [5, 24]. Similar to other polyphenols, reported beneficial effects of quercetin include effects on cardiovascular diseases, cancer, infections, inflammatory processes, gastrointestinal tract function, diabetes (reviewed in [12, 24, 28]), and nervous system disorders, which are discussed below. Previous relevant reviews on the potential for quercetin to exert neuroprotection have been published $[29,30]$.

\section{Neuroprotective Effects of Quercetin: In Vitro Studies}

In vitro studies in neuronal cell lines and in primary neurons have shown that quercetin, at low micromolar concentrations, antagonizes cell toxicity induced by various oxidants (e.g., hydrogen peroxide, linoleic acid hydroperoxide) and other neurotoxic molecules believed to act by inducing oxidative stress (e.g., 6-hydroxydopamine and N-methyl-4phenyl-1,2,3,6-tetrahydropyridinium) [29, 31-34]. A recent study showed that quercetin glycosides (rutin, isoquercitrin) were capable of antagonizing changes in gene expression induced by 6-hydroxydopamine in PC12 cells [35]. In isolated rat brain mitochondria, the toxicity of the anticancer drug oxaliplatin was antagonized by quercetin, which significantly reduced oxidative stress [36]. Protection of neuronal cells from the toxicity of amyloid beta peptide toxicity has also been reported [37].

Experimental conditions (e.g., end-points, duration of incubation) vary significantly in published in vitro studies; however, quercetin exerts neuroprotection in vitro at concentrations that are in the micromolar range [29], which is higher than the concentration found upon in vivo administration. In addition, most of the absorbed quercetin is present as metabolites, which have undergone only limited testing in vitro. Nevertheless, a number of glucuronidated, methylated, and sulfated quercetin metabolites have been shown to have neuroprotective actions in vitro [14-17], though negative results have also been reported [18].

\section{Neuroprotective Effects of Quercetin: Human and Animal Studies In Vivo}

Extensive evidence supports the notion that diets rich in polyphenols and/or supplementation with specific compounds provide beneficial health effects. In particular, polyphenols have been shown to exert protective actions in several pathological conditions such as cardiovascular disease, metabolic disorders, obesity, diabetes, infections, cancer, and neurotoxic/neurodegenerative processes $[12,44-$ 46].

Specific evidence exists on the neuroprotective effects of quercetin [29]. Several studies show that quercetin can exert neuroprotection and antagonize oxidative stress when administered in vivo. For example, oral quercetin (0.5$50 \mathrm{mg} / \mathrm{kg}$ ) was shown to protect rodents from oxidative stress and neurotoxicity induced by various neurotoxic insults [21, 25]. Among metals, quercetin has been shown to provide protection against the neurotoxicity of lead, methylmercury, and tungsten [38, 40,43]. The neurotoxicity of polychlorinated biphenyls, of the insecticide endosulfan, and of MPTP (1-methyl-4-phenyl-1,2,3,6-tetrahydropyridine) has also been shown to be reduced by quercetin in vivo [39, 41, 42]. Table 2 shows some details on the effects of quercetin treatments toward neurotoxicity induced by these compounds. Quercetin also antagonized cognitive impairment induced by feeding mice a high fat diet [47]. It was also neuroprotective in models of intracerebral hemorrhage in rats [48] and protected the retina from apoptotic damage due to ischemiareperfusion injury in a rat model [49]. Of relevance are also some recent findings showing that quercetin ameliorates Alzheimer's disease pathology and related cognitive deficits in an aged triple transgenic Alzheimer's disease mouse model [50]. Of additional interest are the findings that a combined oral supplementation of quercetin and fish oil enhanced neuroprotection in rats exposed to 3-nitropropionic acid or chronically treated with the insecticide rotenone $[51,52]$. The latter is considered an animal model of Parkinson's disease.

\section{Counteracting Oxidative Stress as a General Mechanism of Neuroprotection by Quercetin}

Oxidative stress is recognized as an important factor in a variety of neurodegenerative diseases, as a mediator of the adverse effects of a number of neurotoxicants, and as a mechanism for age-related degenerative processes [53-55]. Oxidative stress occurs when reactive oxygen species (ROS) accumulate in cells, from either excessive production or insufficient neutralization, causing damage to proteins, lipids, and DNA. Mitochondria are a major contributor of cellular ROS; ROS produced in the mitochondria can also target the electron transport chain (e.g., complex I), resulting in a cycle where ROS production increases, followed by ATP depletion and ultimately cell death [56]. Based on these premises, 
TABLE 2: Neuroprotection by quercetin against neurotoxicants in vivo.

\begin{tabular}{|c|c|c|c|c|}
\hline Animal & Neurotoxicant & Quercetin & Effect of quercetin & Ref. \\
\hline $\begin{array}{l}\text { M, F Wistar } \\
\text { rats }\end{array}$ & $\begin{array}{l}\text { Lead ( } 0.2 \% \text { in water through pre- and } \\
\text { postnatal development) }\end{array}$ & $30 \mathrm{mg} / \mathrm{kg} / \mathrm{d}$ for $7 \mathrm{~d}$ starting at PND 60 & $\begin{array}{l}\text { Decreased lipid perox. in } \\
\text { hippocampus; partial reversal of LTP }\end{array}$ & [38] \\
\hline $\begin{array}{l}\text { M Wistar } \\
\text { rats }\end{array}$ & $\begin{array}{l}\text { PCBs (Aroclor 1254) } \\
2 \mathrm{mg} / \mathrm{kg} / \mathrm{d} \text { for } 30 \mathrm{~d} \text { i.p. }\end{array}$ & $50 \mathrm{mg} / \mathrm{kg} / \mathrm{d}$ for $30 \mathrm{~d}$, orally & $\begin{array}{l}\text { Decreased ox. stress in cerebellum; } \\
\text { reduced dopaminergic toxicity }\end{array}$ & [39] \\
\hline $\begin{array}{l}\text { M Wistar } \\
\text { rats }\end{array}$ & $\mathrm{MeHg} 30 \mathrm{mg} / \mathrm{kg} / \mathrm{d}$ for $45 \mathrm{~d}$, orally & $0.5,5$, and $50 \mathrm{mg} / \mathrm{kg} / \mathrm{d}$ for $45 \mathrm{~d}$, orally & $\begin{array}{l}\text { Decreased reduction of GSH, GPx } \\
\qquad(5,50 \mathrm{mg} / \mathrm{kg})\end{array}$ & [40] \\
\hline $\begin{array}{l}\mathrm{M} \mathrm{C} 57 \mathrm{BL} / 6 \\
\text { mice }\end{array}$ & MPTP $30 \mathrm{mg} / \mathrm{kg} / \mathrm{d}$ for $4 \mathrm{~d}(10-14$ of Q) & 50,100 , and $200 \mathrm{mg} / \mathrm{kg} / \mathrm{d}$ for $14 \mathrm{~d}$ & $\begin{array}{l}\text { Diminished reduction of DA levels, } \\
\text { SOD, and GPX }\end{array}$ & [41] \\
\hline $\begin{array}{l}\text { M Wistar } \\
\text { rats }\end{array}$ & Endosulfan $2 \mathrm{mg} / \mathrm{kg} / \mathrm{d}$, for $6 \mathrm{~d}$, orally & $10 \mathrm{mg} / \mathrm{kg} / \mathrm{d}$, for $6 \mathrm{~d}$, orally & $\begin{array}{l}\text { Diminished lipid perox. and } \\
\text { mitochondria swelling }\end{array}$ & [42] \\
\hline $\begin{array}{l}\text { M Wistar } \\
\text { rats }\end{array}$ & Tungsten $100 \mathrm{ppm}$ in water for $3 \mathrm{mo}$. & $0.3 \mathrm{mM} / \mathrm{d}$ for $3 \mathrm{mo}$. , orally & Reduced oxidative stress & [43] \\
\hline
\end{tabular}

F: female; GPx: glutathione peroxidase; GSH: glutathione; M: male; MeHg: methylmercury; MPTP: 1-methyl-4-phenyl-1,2,3,6-tetrahydropyridine; PCBs: polychlorinated biphenyls; PND: postnatal day; SOD: superoxide dismutase.

the identification of novel compounds which can counteract oxidative stress as potential therapeutics is a very active area of research [57]. Natural compounds have received much attention in this regard, and polyphenols such as quercetin have been the most investigated $[29,58]$.

5.1. Quercetin as a Direct Antioxidant. Quercetin is a potent scavenger of ROS, such as $\mathrm{O}_{2}{ }^{\circ-}$, and of RNS (reactive nitrogen species), such as NO and ONOO [28]. The antioxidant capacity of quercetin has been ascribed to the presence of two pharmacophores within the molecule that have the optimal configuration for free radical scavenging, that is, the catechol group in the $\mathrm{B}$ ring and the $\mathrm{OH}$ group at position 3 [28]. At concentrations of 5 to $50 \mu \mathrm{M}$ quercetin can directly scavenge ROS in vitro [59]. However, the concentration of quercetin expected to be present in the brain would likely be in the nanomolar range, well below that necessary to exert an appreciable direct antioxidant effect. In contrast, other important antioxidants, such as glutathione and vitamin C, are present at millimolar concentrations [22]. Thus, despite its potent antioxidant capacity in vitro, it is unlikely that neuroprotective effects of quercetin observed in vivo are due to a direct antioxidant action. Rather, it has been suggested that quercetin and/or its metabolites may act by modulating the cell's own antioxidant defense mechanisms [60, 61], suggesting that quercetin may act as a prooxidant, rather than an antioxidant $[62,63]$. A mild degree of oxidative stress may indeed increase the cell's own antioxidant defenses, resulting in overall cytoprotection.

5.2. Modulation of Antioxidant Pathways by Quercetin. As indicated, quercetin may have prooxidant, rather than antioxidant, properties $[28,62,63]$. In the process of antioxidant activities, quercetin oxidizes into various oxidation products, including semiquinone radicals and quinones [28]. Interestingly, such compounds may mediate the toxic effects of quercetin observed in certain conditions [28, 63]. Evidence is emerging to support hormetic roles for small increases in membrane and mitochondrial oxidative stress [64]. Hormesis, which is generally defined as a dose-response phenomenon characterized by low-dose stimulation and highdose inhibition, also includes the phenomenon of "preconditioning," in which exposure to a low dose of an agent that is toxic at high doses induces an adaptive, potentially beneficial effect on the cell or organism if exposed to a subsequent and more massive dose of the same or related stressor agent [65].

5.2.1. The Nrf2-ARE Pathway. Nrf2 [nuclear factor (erythroid-derived 2)-like 2] is an important regulator of cellular defense against oxidative stress. Under physiological conditions, Nrf2 is sequestered in the cytoplasm by the protein Keap1 (Kelch-like ECH-associated protein 1) with Cullin 3-base E3 ligase, resulting in the ubiquitination of the Nrf2 protein and its targeting for proteasomal degradation [66-68]. Keap1 has several cysteine residues which make it act as a molecular switch, responding to electrophiles and ROS with a conformational change which releases Nrf2 [66]. Dissociated Nrf2 translocates into the nucleus where it binds to small Maf proteins. The formed heterodimer binds to cis-acting antioxidant response elements (ARE) and thereby promotes the transcription of a broad range of phase II and antioxidant genes [67, 68]. Proteins under control of the Nrf2-ARE pathway include heme oxygenase-1, glutamate cysteine ligase, glutathione S-transferases, glutathione peroxidase, superoxide dismutase, catalase, sulfiredoxin, and thioredoxin $[66,68]$.

Activation of the Nrf2-ARE pathway provides neuroprotection against oxidative damage and cell death. More recent evidence also suggests that the Nrf2-ARE pathway may modulate the formation and degradation of misfolded protein aggregates which are present in various neurodegenerative diseases (Parkinson's, Alzheimer's, and Huntington's diseases and amyotrophic lateral sclerosis) [68]. For example, studies with tert-butylhydroquinone, a prototype Nrf2 inducer, have shown that activation of the Nrf2-ARE pathway confers protection against neurotoxicity induced by amyloid beta and 3-nitropropionic acid [66-69]. 
Quercetin has been shown to counteract oxidative stressinduced cellular damage by activating the Nrf2-ARE pathway $[33,59,70]$, and similar effects have been reported for dihydroquercetin [67]. Additionally, other nutraceuticals (e.g., kaempferol, pterostilbene) have been shown to interact synergistically with quercetin in this regard [59]. Pathways involved in the activation of Nrf2 include the ERK and JNK signaling [67], and they in turn are activated by stress stimuli including mild oxidative stress, suggesting that quercetin may act as a neurohormetic phytochemical [71].

5.2.2. The Paraoxonase 2 (PON2) Pathway. PON2 is a member of the paraoxonase family of genes which also includes PON1 and PON3. PON2 does not have esterase activity but is a potent lactonase [72] and plays a significant role in atherosclerosis [73]. In contrast to PON1 and PON3, which are present primarily in the liver and in blood, PON2 is a ubiquitously expressed intracellular enzyme [74-76]. PON2 mRNA has been found in mouse and human brain, and PON2 protein has been detected in mouse [75-77], rat, human, and monkey brain ([78]; Costa et al., unpublished). In mouse brain the highest levels of PON2 protein were found in dopaminergic regions, while, at the cellular level, PON2 is higher in astrocytes than in neurons or microglia. Subcellular distribution studies have shown that PON2 is localized primarily in the mitochondria $[76,79]$. Interestingly, female mice express higher levels of PON2 than males, and this sex difference has been also seen in other species (rat, human, and monkey) ([76, 78, 80]; Costa et al., unpublished). This may be related to a positive modulatory effect by estrogens. Indeed, 17-beta-estradiol increases PON2 expression, possibly by activating the alpha estrogen receptor [78].

PON2 has been shown to exert an antioxidant effect, which is believed to play a major role in preventing the atherosclerotic process and in neuroprotection [76, 79-81]. The preponderant localization of PON2 in mitochondria would support a role for this enzyme in protecting cells from oxidative damage. In HeLa cells, PON2 has been shown to bind to coenzyme Q10 that associates with complex III in mitochondria, and PON2 deficiency causes mitochondrial dysfunction [79]. In human endothelial cells PON2 has been shown to reduce, indirectly but specifically, the release of superoxide from the inner mitochondrial membrane, without affecting levels of other radicals such as hydrogen peroxide and peroxynitrite [82]. Of relevance is also the fact that mitochondria, together with the cytoplasm and the nucleus, are preferential accumulation sites for quercetin in cells [83].

The cytotoxicity of two known oxidants, hydrogen peroxide $\left(\mathrm{H}_{2} \mathrm{O}_{2}\right)$ and 2,3-dimethoxy-1,4-naphthoquinone (DMNQ), is much higher in cells from PON2 $2^{-/-}$mice [76]. Similarly, striatal astrocytes and neurons from male mice (which express low PON2 levels) are more sensitive to $\mathrm{H}_{2} \mathrm{O}_{2}$ - and DMNQ-induced oxidative stress and ensuing cytotoxicity than female cells [78].

Given the antioxidant actions of PON2 in the CNS, a positive modulation of PON2 may result in neuroprotection [80]. In macrophages, PON2 expression is increased by oxidative stress [84], and in vascular cells an endoplasmic reticulum
TABLE 3: Protective effect of quercetin against oxidative stress and cytotoxicity in mouse striatal astrocytes.

\begin{tabular}{ccc}
\hline & ROS $(\%$ of basal $)$ & Cytotoxicity $\left(\mathrm{IC}_{50}, \mu \mathrm{M}\right)$ \\
\hline Control & & \\
$\mathrm{H}_{2} \mathrm{O}_{2}$ & 630 & 39 \\
DMNQ & 695 & 37 \\
\hline+ Quercetin & & \\
$\mathrm{H}_{2} \mathrm{O}_{2}$ & $130^{*}$ & $157^{*}$ \\
DMNQ & $115^{*}$ & $131^{*}$ \\
\hline
\end{tabular}

For ROS measurements, control or quercetin-pretreated cells (24 h, $20 \mu \mathrm{M})$ were exposed to either oxidant for $30 \mathrm{~min}$. For cytotoxicity (assessed by the MTT assay) control or quercetin pretreated cells were exposed for $24 \mathrm{~h}$ to 4 5 concentrations of oxidants. ${ }^{*}$ Significantly different from control, $p<0.01$. Adapted from [34].

stress element-like sequence was found to be present in the promoter region of PON2 [81]. Various compounds have been shown to upregulate PON2 expression in various tissues or cell types (see details in [85]).

Quercetin was reported to increase PON2 mRNA and protein in macrophages in vitro, though administration of $150 \mathrm{mg} /$ day to human volunteers for six weeks was without effect [86]. Another recent study examined the induction of PON2 by quercetin in brain cells in vitro [34]. Quercetin increases PON2 protein expression in mouse striatal astrocytes and neurons and in macrophages. The effect of quercetin is antagonized by SP600125, an inhibitor of the JNK/AP-1 pathway, but not by the PPAR gamma inhibitor GW9662. One possibility is that quercetin may induce a very low level of oxidative stress $[62,87]$, which in turn would modulate the JNK/AP-1 pathway [88], causing an increase in PON2 expression. Alternatively, given the effects of estradiol on PON2 expression [78], quercetin may induce PON2 expression by virtue of its phytoestrogen activity ([17, 89]; see also Section 9).

Independent of the underlying mechanism(s), the ability of quercetin to induce PON2 may play a role in its neuroprotective actions. Indeed, in striatal astrocytes from wildtype mice, quercetin abolished the increase in ROS levels and the cytotoxicity induced by $\mathrm{H}_{2} \mathrm{O}_{2}$ or DMNQ, providing a 4fold protection (Table 3 ). In contrast, in cells from PON2 $2^{-/-}$ mice the toxicity of $\mathrm{H}_{2} \mathrm{O}_{2}$ and DMNQ was decreased by less than 2-fold; this partial protection may be due to Nrf2-ARE induction [34].

\section{Induction of Autophagy}

An additional mechanism for quercetin neuroprotection relates to the modulation of autophagy. Autophagy (from the Greek "to eat oneself") refers to the cellular degradative pathways that involve delivery of the cytoplasmatic cargo to the lysosomes [90-92]. Autophagy (macroautophagy) is a multistep process involving the formation of double membrane structures, the autophagosomes, which then fuse with lysosomes. The content of the resulting autophagolysosomes (misfolded proteins, cellular metabolic waste) is then 
degraded by hydrolytic enzymes. Autophagy is also important for removal of damaged mitochondria and of normal mitochondria undergoing turnover, in a process known as mitophagy. The integrity of the CNS is highly dependent on normal basal autophagy, as damaged organelles and misfolded proteins would accumulate in neurons unless they are successfully removed [90]. Rapamycin, an inhibitor of mTOR (mammalian target of rapamycin) activity, is a potent inducer of autophagy and acts as a neuroprotector $[92,93]$. In contrast, deletion of key autophagy genes (Atg5, Atg7) causes severe neurodegeneration [94]. Stimulation of autophagy in the CNS would thus lead to neuroprotection, as has been shown for various compounds [92]. Quercetin has been shown to alleviate cell damage caused in Schwann cells by high glucose by inducing autophagy [95]. Similarly, in $C$. elegans, the neurotoxicity of amyloid beta 1-42 is antagonized by quercetin through induction of autophagy [96].

\section{Modulation of Sirtuins}

An additional field of interest with regard to the mechanisms of neuroprotection provided by quercetin is that of sirtuins. These proteins (in mammals there are seven, named SIRT1 to SIRT7) are involved in a variety of cellular and molecular processes and pathways, with distinct cellular localization and molecular targets [97]. Of these, SIRT1 predominantly localizes in the nucleus and acts as a deacetylase for histones and other targets. SIRT1 protects cells from apoptosis and promotes differentiation of stem cells. SIRT2 is prevalently in the cytoplasm and has been found to accumulate in neurons, while other SIRTs localize primarily in the mitochondria [97]. The neuroprotective effects of quercetin may also involve activation of SIRT1, which would lead to suppression of Baxdependent apoptosis and repression of multiple proapoptotic transcription factors. A recent example of the effects of quercetin on this pathway is represented by findings showing that quercetin inhibits herpes simplex virus type 1-induced neurodegeneration by activating SIRT1 [98].

\section{Modulation of Neuroinflammation}

Neuroinflammation is emerging as playing a most relevant role in neurodevelopmental and neurodegenerative disorders and thus represents a potential important target for therapeutic interventions $[99,100]$. Compounds that may antagonize microglia activation and reduce the release of proinflammatory cytokines would be of much relevance. Some isoflavones are suggested to reduce microglial activation and subsequent release of proinflammatory factors [101], and polyphenols may have beneficial anti-inflammatory properties [45]. Quercetin has been shown to reduce lipopolysaccharide(LPS-) induced nitric oxide release from a mouse neuroglia cell line [102]; a similar effect on LPS-induced proinflammatory cytokines was reported in another mouse microglial cell line [103]. In addition, quercetin also inhibits cytokine production by astrocytes [104]. The cellular/molecular mechanisms for the anti-inflammatory effects of quercetin are not known, but a possible pathway may be related to induction of
PON2 which has anti-inflammatory activity in addition to its antioxidant activity.

\section{Quercetin as a Phytoestrogen}

As indicated earlier, induction of PON2 expression by quercetin may be ascribed to its phytoestrogen activity. The classification of quercetin as a phytoestrogen is still controversial $[105,106]$, and so is the potential involvement of estrogen alpha or beta receptors in its action [89, 107]. Nevertheless, both the quercetin aglycone and its glucuronide have been recently shown to possess estrogenic activity and to activate estrogen receptor alpha [17]. The neuroprotective actions of estrogens are well known, though the exact mechanisms are not fully understood [108, 109]. Interestingly, the protective effect of estradiol was absent in cells from PON2 $2^{-/-}$mice, suggesting that a major mechanism of estrogen neuroprotection may be represented by induction of PON2 [78]. Identical findings have been reported with regard to quercetin [34]. Thus, additional studies on the role of estrogen receptor pathways in neuroprotection by quercetin would be relevant.

\section{Conclusion}

There is an increasing interest for the potential neuroprotective effects of quercetin and other nutraceuticals. This brief review has focused on mechanisms related to the ability of quercetin to counteract oxidative stress-mediated neurotoxicity and on some additional potential mechanisms of neuroprotection. However, further targets for biological activity are to be expected, for example, related to signal transduction pathways, proteasome function, mitochondrial integrity, and so on [24]. An important issue to consider as part of a discussion on the beneficial effects of quercetin remains to be that of increasing its access to the CNS, and notable progress has been made in recent years in this regard. In addition, the potential role played by quercetin metabolites should be examined more systematically, as only limited information is available [110].

\section{Conflict of Interests}

The authors declare that they have no conflict of interests.

\section{Authors' Contribution}

Lucio G. Costa wrote the first draft of the paper; Claudia Pellacani, Jacqueline M. Garrick, and Pamela J. Roquè provided extensive comments and corrections; Claudia Pellacani drew the figure. All authors read and approved the final paper.

\section{Acknowledgment}

Part of the work by the authors was supported by grants from NIEHS (P30ES07033, P42ES04696). 


\section{References}

[1] USDA (United States Department of Agriculture), USDA Database for the Flavonoid Content of Selected Foods, USDA, Beltsville Human Nutrition Research Center, Beltsville, Md, USA, 2003.

[2] D. Del Rio, A. Rodriguez-Mateos, J. P. E. Spencer, M. Tognolini, G. Borges, and A. Crozier, "Dietary (poly)phenolics in human health: structures, bioavailability, and evidence of protective effects against chronic diseases," Antioxidants \& Redox Signaling, vol. 18, no. 14, pp. 1818-1892, 2013.

[3] K. Kawabata, R. Mukai, and A. Ishisaka, "Quercetin and related polyphenols: new insights and implications for their bioactivity and bioavailability," Food \& Function, vol. 6, no. 5, pp. 1399-1417, 2015.

[4] H. Nishimuro, H. Ohnishi, M. Sato et al., "Estimated daily intake and seasonal food sources of quercetin in Japan," Nutrients, vol. 7, no. 4, pp. 2345-2358, 2015.

[5] M. Harwood, B. Danielewska-Nikiel, J. F. Borzelleca, G. W. Flamm, G. M. Williams, and T. C. Lines, "A critical review of the data related to the safety of quercetin and lack of evidence of in vivo toxicity, including lack of genotoxic/carcinogenic properties," Food and Chemical Toxicology, vol. 45, no. 11, pp. 21792205, 2007.

[6] Y. Guo and R. S. Bruno, "Endogenous and exogenous mediators of quercetin bioavailability," The Journal of Nutritional Biochemistry, vol. 26, no. 3, pp. 201-210, 2015.

[7] V. C. J. de Boer, A. A. Dihal, H. van der Woude et al., "Tissue distribution of quercetin in rats and pigs," The Journal of Nutrition, vol. 135, no. 7, pp. 1718-1725, 2005.

[8] C. Manach, G. Williamson, C. Morand, A. Scalbert, and C. Rémésy, "Bioavailability and bioefficacy of polyphenols in humans. I. Review of 97 bioavailability studies," The American Journal of Clinical Nutrition, vol. 81, no. 1, supplement, pp. 230S242S, 2005.

[9] J. A. Conquer, G. Maiani, E. Azzini, A. Raguzzini, and B. J. Holub, "Supplementation with quercetin markedly increases plasma quercetin concentration without effect on selected risk factors for heart disease in healthy subjects," The Journal of Nutrition, vol. 128, no. 3, pp. 593-597, 1998.

[10] C. Manach, A. Scalbert, C. Morand, C. Rémésy, and L. Jiménez, "Polyphenols: food sources and bioavailability", The American Journal of Clinical Nutrition, vol. 79, no. 5, pp. 727-747, 2004.

[11] R. A. Shanely, A. M. Knab, D. C. Nieman, F. Jin, S. R. McAnulty, and M. J. Landram, "Quercetin supplementation does not alter antioxidant status in humans," Free Radical Research, vol. 44, no. 2, pp. 224-231, 2010.

[12] G. S. Kelly, "Quercetin. Monograph," Alternative Medicine Review, vol. 16, no. 2, pp. 172-194, 2011.

[13] J.-H. Moon, T. Tsushida, K. Nakahara, and J. Terao, "Identification of quercetin 3-O- $\beta$-D-glucuronide as an antioxidative metabolite in rat plasma after oral administration of quercetin," Free Radical Biology and Medicine, vol. 30, no. 11, pp. 1274-1285, 2001.

[14] M. Shirai, Y. Kawai, R. Yamanishi, T. Kinoshita, H. Chuman, and J. Terao, "Effect of a conjugated quercetin metabolite, quercetin 3-glucuronide, on lipid hydroperoxide-dependent formation of reactive oxygen species in differentiated PC-12 cells," Free Radical Research, vol. 40, no. 10, pp. 1047-1053, 2006.

[15] S.-L. Yeh, C.-L. Yeh, S.-T. Chan, and C.-H. Chuang, "Plasma rich in quercetin metabolites induces $\mathrm{G}_{2} / \mathrm{M}$ arrest by upregulating
PPAR- $\gamma$ expression in human A549 lung cancer cells," Planta Medica, vol. 77, no. 10, pp. 992-998, 2011.

[16] C. Boesch-Saadatmandi, A. Loboda, A. E. Wagner et al., "Effect of quercetin and its metabolites isorhamnetin and quercetin-3glucuronide on inflammatory gene expression: role of miR-155," Journal of Nutritional Biochemistry, vol. 22, no. 3, pp. 293-299, 2011.

[17] R. Ruotolo, L. Calani, F. Brighenti, A. Crozier, S. Ottonello, and D. Del Rio, "Glucuronidation does not suppress the estrogenic activity of quercetin in yeast and human breast cancer cell model systems," Archives of Biochemistry and Biophysics, vol. 559, pp. 62-67, 2014.

[18] J. M. Cho, S.-Y. Chang, D.-B. Kim, P. W. Needs, Y.-H. Jo, and M.-J. Kim, "Effects of physiological quercetin metabolites on interleukin- $\beta$-induced inducible NOS expression," Journal of Nutritional Biochemistry, vol. 23, no. 11, pp. 1394-1402, 2012.

[19] M. Fiorani, A. Accorsi, and O. Cantoni, "Human red blood cells as a natural flavonoid reservoir," Free Radical Research, vol. 37, no. 12, pp. 1331-1338, 2003.

[20] A. Faria, D. Pestana, D. Teixeira et al., "Flavonoid transport across RBE4 cells: a blood-brain barrier model," Cellular and Molecular Biology Letters, vol. 15, no. 2, pp. 234-241, 2010.

[21] A. Ishisaka, S. Ichikawa, H. Sakakibara et al., "Accumulation of orally administered quercetin in brain tissue and its antioxidative effects in rats," Free Radical Biology and Medicine, vol. 51, no. 7, pp. 1329-1336, 2011.

[22] S. Schaffer and B. Halliwell, "Do polyphenols enter the brain and does it matter? Some theoretical and practical considerations," Genes and Nutrition, vol. 7, no. 2, pp. 99-109, 2012.

[23] P. Huebbe, A. E. Wagner, C. Boesch-Saadatmandi, F. Sellmer, S. Wolffram, and G. Rimbach, "Effect of dietary quercetin on brain quercetin levels and the expression of antioxidant and Alzheimer's disease relevant genes in mice," Pharmacological Research, vol. 61, no. 3, pp. 242-246, 2010.

[24] M. Russo, C. Spagnuolo, I. Tedesco, S. Bilotto, and G. L. Russo, "The flavonoid quercetin in disease prevention and therapy: facts and fancies," Biochemical Pharmacology, vol. 83, no. 1, pp. 6-15, 2012.

[25] S. Das, A. K. Mandal, A. Ghosh, S. Panda, N. Das, and S. Sarkar, "Nanoparticulated quercetin in combating age related cerebral oxidative injury," Current Aging Science, vol. 1, no. 3, pp. 169-174, 2008.

[26] S. Dhawan, R. Kapil, and B. Singh, "Formulation development and systematic optimization of solid lipid nanoparticles of quercetin for improved brain delivery," Journal of Pharmacy and Pharmacology, vol. 63, no. 3, pp. 342-351, 2011.

[27] P. Ferri, D. Angelino, L. Gennari et al., "Enhancement of flavonoid ability to cross the blood-brain barrier of rats by coadministration with $\alpha$-tocopherol," Food \& Function, vol. 6, no. 2, pp. 394-400, 2015.

[28] A. W. Boots, G. R. M. M. Haenen, and A. Bast, "Health effects of quercetin: from antioxidant to nutraceutical," European Journal of Pharmacology, vol. 585, no. 2-3, pp. 325-337, 2008.

[29] B. Ossola, T. M. Kääriäinen, and P. T. Männistö, "The multiple faces of quercetin in neuroprotection," Expert Opinion on Drug Safety, vol. 8, no. 4, pp. 397-409, 2009.

[30] F. Dajas, "Life or death: neuroprotective and anticancer effects of quercetin," Journal of Ethnopharmacology, vol. 143, no. 2, pp. 383-396, 2012.

[31] L. D. Mercer, B. L. Kelly, M. K. Horne, and P. M. Beart, "Dietary polyphenols protect dopamine neurons from oxidative insults 
and apoptosis: investigations in primary rat mesencephalic cultures," Biochemical Pharmacology, vol. 69, no. 2, pp. 339-345, 2005.

[32] D. Vauzour, G. Ravaioli, K. Vafeiadou, A. Rodriguez-Mateos, C. Angeloni, and J. P. E. Spencer, "Peroxynitrite induced formation of the neurotoxins 5-S-cysteinyl-dopamine and DHBT-1: implications for Parkinson's disease and protection by polyphenols," Archives of Biochemistry and Biophysics, vol. 476, no. 2, pp. 145151, 2008.

[33] F. Arredondo, C. Echeverry, J. A. Abin-Carriquiry et al., "After cellular internalization, quercetin causes Nrf2 nuclear translocation, increases glutathione levels, and prevents neuronal death against an oxidative insult," Free Radical Biology and Medicine, vol. 49, no. 5, pp. 738-747, 2010.

[34] L. G. Costa, L. Tait, R. De Laat et al., "Modulation of paraoxonase 2 (PON2) in mouse brain by the polyphenol quercetin: a mechanism of neuroprotection?" Neurochemical Research, vol. 38, no. 9, pp. 1809-1818, 2013.

[35] K. B. Magalingam, A. Radhakrishnan, P. Ramdas, and N. Haleagrahara, "Quercetin glycosides induced neuroprotection by changes in the gene expression in a cellular model of Parkinson's disease," Journal of Molecular Neuroscience, vol. 55, no. 3, pp. 609-617, 2015.

[36] M. Waseem and S. Parvez, "Neuroprotective activities of curcumin and quercetin with potential relevance to mitochondrial dysfunction induced by oxaliplatin," Protoplasma, 2015.

[37] M. A. Ansari, H. M. Abdul, G. E. Joshi, W. O. Opii, and D. A. Butterfield, "Protective effect of quercetin in primary neurons against Abeta(1-42): relevance to Alzheimer's disease," Journal of Nutritional Biochemistry, vol. 20, no. 4, pp. 269-275, 2009.

[38] P. Hu, M. Wang, W.-H. Chen et al., "Quercetin relieves chronic lead exposure-induced impairment of synaptic plasticity in rat dentate gyrus in vivo," Naunyn-Schmiedeberg's Archives of Pharmacology, vol. 378, no. 1, pp. 43-51, 2008.

[39] S. Bavithra, K. Selvakumar, R. P. Kumari, G. Krishnamoorthy, P. Venkataraman, and J. Arunakaran, "Polychlorinated biphenyl (PCBs)-induced oxidative stress plays a critical role on cerebellar dopaminergic receptor expression: ameliorative role of quercetin," Neurotoxicity Research, vol. 21, no. 2, pp. 149-159, 2012.

[40] G. R. M. Barcelos, D. Grotto, J. M. Serpeloni et al., "Protective properties of quercetin against DNA damage and oxidative stress induced by methylmercury in rats," Archives of Toxicology, vol. 85, no. 9, pp. 1151-1157, 2011.

[41] C. Lv, T. Hong, Z. Yang et al., "Effect of quercetin in the 1methyl-4-phenyl-1, 2, 3, 6-tetrahydropyridine-induced mouse model of Parkinson's disease," Evidence-Based Complementary and Alternative Medicine, vol. 2012, Article ID 928643, 6 pages, 2012.

[42] Z. Lakroun, M. Kebieche, A. Lahouel, D. Zama, F. Desor, and R. Soulimani, "Oxidative stress and brain mitochondria swelling induced by endosulfan and protective role of quercetin in rat," Environmental Science and Pollution Research, vol. 22, no. 10, pp. 7776-7781, 2015.

[43] S. Sachdeva, S. C. Pant, P. Kushwaha, R. Bhargava, and S. J. S. Flora, "Sodium tungstate induced neurological alterations in rat brain regions and their response to antioxidants," Food and Chemical Toxicology, vol. 82, pp. 64-71, 2015.

[44] I. C. W. Arts and P. C. H. Hollman, "Polyphenols and disease risk in epidemiologic studies," The American Journal of Clinical Nutrition, vol. 81, supplement, pp. 317S-325S, 2005.
[45] D. Vauzour, "Dietary polyphenols as modulators of brain functions: biological actions and molecular mechanisms underpinning their beneficial effects," Oxidative Medicine and Cellular Longevity, vol. 2012, Article ID 914273, 16 pages, 2012.

[46] K. S. Bhullar and H. P. V. Rupasinghe, "Polyphenols: multipotent therapeutic agents in neurodegenerative diseases," Oxidative Medicine and Cellular Longevity, vol. 2013, Article ID 891748, 18 pages, 2013.

[47] S.-F. Xia, Z.-X. Xie, Y. Qiao et al., "Differential effects of quercetin on hippocampus-dependent learning and memory in mice fed with different diets related with oxidative stress," Physiology and Behavior, vol. 138, pp. 325-331, 2015.

[48] Y. Zhang, B. Yi, J. Ma et al., "Quercetin promotes neuronal and behavioral recovery by suppressing inflammatory response and apoptosis in a rat model of intracerebral hemorrhage," Neurochemical Research, vol. 40, no. 1, pp. 195-203, 2015.

[49] S. Arikan, I. Ersan, T. Karaca et al., "Quercetin protects the retina by reducing apoptosis due to ischemia-reperfusion injury in a rat model," Arquivos Brasileiros de Oftalmologia, vol. 78, no. 2, pp. 100-104, 2015.

[50] A. M. Sabogal-Guáqueta, J. I. Muñoz-Manco, J. R. RamírezPineda, M. Lamprea-Rodriguez, E. Osorio, and G. P. CardonaGómez, "The flavonoid quercetin ameliorates Alzheimer's disease pathology and protects cognitive and emotional function in aged triple transgenic Alzheimer's disease model mice," Neuropharmacology, vol. 93, pp. 134-145, 2015.

[51] K. M. Denny Joseph and Muralidhara, "Enhanced neuroprotective effect of fish oil in combination with quercetin against 3-nitropropionic acid induced oxidative stress in rat brain," Progress in Neuro-Psychopharmacology and Biological Psychiatry, vol. 40, no. 1, pp. 83-92, 2013.

[52] K. M. Denny Joseph and Muralidhara, "Combined oral supplementation of fish oil and quercetin enhances neuroprotection in a chronic rotenone rat model: relevance to Parkinson's disease," Neurochemical Research, vol. 40, no. 5, pp. 894-905, 2015.

[53] M. T. Lin and M. F. Beal, "Mitochondrial dysfunction and oxidative stress in neurodegenerative diseases," Nature, vol. 443, no. 7113, pp. 787-795, 2006.

[54] I. Martin and M. S. Grotewiel, "Oxidative damage and agerelated functional declines," Mechanisms of Ageing and Development, vol. 127, no. 5, pp. 411-423, 2006.

[55] A. Popa-Wagner, S. Mitran, S. Sivanesan, E. Chang, and A.-M. Buga, "ROS and brain diseases: the good, the bad, and the ugly," Oxidative Medicine and Cellular Longevity, vol. 2013, Article ID 963520, 14 pages, 2013.

[56] M. Ott, V. Gogvadze, S. Orrenius, and B. Zhivotovsky, "Mitochondria, oxidative stress and cell death," Apoptosis, vol. 12, no. 5, pp. 913-922, 2007.

[57] D. A. Linseman, "Targeting oxidative stress for neuroprotection," Antioxidants and Redox Signaling, vol. 11, no. 3, pp. 421424, 2009.

[58] J. P. E. Spencer, "Flavonoids and brain health: multiple effects underpinned by common mechanisms," Genes \& Nutrition, vol. 4, no. 4, pp. 243-250, 2009.

[59] C. L. L. Saw, Y. Guo, A. Y. Yang et al., “The berry constituents quercetin, kaempferol, and pterostilbene synergistically attenuate reactive oxygen species: involvement of the Nrf2-ARE signaling pathway," Food and Chemical Toxicology, vol. 72, pp. 303-311, 2014.

[60] B. Halliwell, J. Rafter, and A. Jenner, "Health promotion by flavonoids, tocopherols, tocotrienols, and other phenols: direct 
or indirect effects? Antioxidant or not?" The American Journal of Clinical Nutrition, vol. 81, no. 1, supplement, pp. 268S-276S, 2005.

[61] C. G. Fraga, M. Galleano, S. V. Verstraeten, and P. I. Oteiza, "Basic biochemical mechanisms behind the health benefits of polyphenols," Molecular Aspects of Medicine, vol. 31, no. 6, pp. 435-445, 2010.

[62] B. Halliwell, "Are polyphenols antioxidants or pro-oxidants? What do we learn from cell culture and in vivo studies?" Archives of Biochemistry and Biophysics, vol. 476, no. 2, pp. 107$112,2008$.

[63] B. Halliwell, "The antioxidant paradox: less paradoxical now?" British Journal of Clinical Pharmacology, vol. 75, no. 3, pp. 637644, 2013.

[64] V. Calabrese, C. Cornelius, A. T. Dinkova-Kostova, E. J. Calabrese, and M. P. Mattson, "Cellular stress responses, the hormesis paradigm, and vitagenes: novel targets for therapeutic intervention in neurodegenerative disorders," Antioxidants and Redox Signaling, vol. 13, no. 11, pp. 1763-1811, 2010.

[65] E. J. Calabrese, K. A. Bachmann, A. J. Bailer, P. M. Bolger et al., "Biological stress response terminology: integrating the concepts of adaptive response and pre-conditioning stress with hormetic dose-response framework," Toxicology and Applied Pharmacology, vol. 222, no. 1, pp. 122-128, 2007.

[66] A. Y. Shih, S. Imbeault, V. Barakauskas et al., "Induction of the Nrf2-driven antioxidant response confers neuroprotection during mitochondrial stress in vivo," Journal of Biological Chemistry, vol. 280, no. 24, pp. 22925-22936, 2005.

[67] L. Liang, C. Gao, M. Luo et al., "Dihydroquercetin (DHQ) induced HO-1 and NQO1 expression against oxidative stress through the Nrf2-dependent antioxidant pathway," Journal of Agricultural and Food Chemistry, vol. 61, no. 11, pp. 2755-2761, 2013.

[68] L. Gan and J. A. Johnson, "Oxidative damage and the Nrf2ARE pathway in neurodegenerative diseases," Biochimica et Biophysica Acta (BBA)-Molecular Basis of Disease, vol. 1842, no. 8, pp. 1208-1218, 2014.

[69] F. Nouhi, S. K. Tusi, A. Abdi, and F. Khodagholi, "Dietary supplementation with $\mathrm{tBHQ}$, an NRF2 stabilizer molecule, confers neuroprotection against apoptosis in amyloid- $\beta$-injected rat," Neurochemical Research, vol. 36, no. 5, pp. 870-878, 2011.

[70] A. B. Granado-Serrano, M. A. Martín, L. Bravo, L. Goya, and S. Ramos, "Quercetin modulates Nrf2 and glutathionerelated defenses in HepG2 cells: involvement of p38," ChemicoBiological Interactions, vol. 195, no. 2, pp. 154-164, 2012.

[71] M. P. Mattson and A. Cheng, "Neurohormetic phytochemicals: low-dose toxins that induce adaptive neuronal stress responses," Trends in Neurosciences, vol. 29, no. 11, pp. 632-639, 2006.

[72] D. I. Draganov, J. F. Teiber, A. Speelman, Y. Osawa, R. Sunahara, and B. N. La Du, "Human paraoxonases (PON1, PON2, and PON3) are lactonases with overlapping and distinct substrate specificities," Journal of Lipid Research, vol. 46, no. 6, pp. 12391247, 2005.

[73] C. J. Ng, N. Bourquard, V. Grijalva et al., "Paraoxonase-2 deficiency aggravates atherosclerosis in mice despite lower apolipoprotein-B-containing lipoproteins: anti-atherogenic role for paraoxonase-2," The Journal of Biological Chemistry, vol. 281, no. 40, pp. 29491-29500, 2006.

[74] C. J. Ng, D. J. Wadleigh, A. Gangopadhyay et al., "Paraoxonase-2 is a ubiquitously expressed protein with antioxidant properties and is capable of preventing cell-mediated oxidative modification of low density lipoprotein," Journal of Biological Chemistry, vol. 276, no. 48, pp. 44444-44449, 2001.

[75] J. Marsillach, B. Mackness, M. Mackness et al., "Immunohistochemical analysis of paraoxonases-1, 2, and 3 expression in normal mouse tissues," Free Radical Biology and Medicine, vol. 45, no. 2, pp. 146-157, 2008.

[76] G. Giordano, T. B. Cole, C. E. Furlong, and L. G. Costa, "Paraoxonase 2 (PON2) in the mouse central nervous system: a neuroprotective role?" Toxicology and Applied Pharmacology, vol. 256, no. 3, pp. 369-378, 2011.

[77] S. L. Primo-Parmo, R. C. Sorenson, J. Teiber, and B. N. La Du, "The human serum paraoxonase/arylesterase gene (PON1) is one member of a multigene family," Genomics, vol. 33, no. 3, pp. 498-507, 1996.

[78] G. Giordano, L. Tait, C. E. Furlong, T. B. Cole, T. J. Kavanagh, and L. G. Costa, "Gender differences in brain susceptibility to oxidative stress are mediated by levels of paraoxonase- 2 expression," Free Radical Biology and Medicine, vol. 58, pp. 98108, 2013.

[79] A. Devarajan, N. Bourquard, S. Hama et al., "Paraoxonase 2 deficiency alters mitochondrial function and exacerbates the development of atherosclerosis," Antioxidants and Redox Signaling, vol. 14, no. 3, pp. 341-351, 2011.

[80] L. G. Costa, R. de Laat, K. Dao, C. Pellacani, T. B. Cole, and C. E. Furlong, "Paraoxonase-2 (PON2) in brain and its potential role in neuroprotection," NeuroToxicology, vol. 43, pp. 3-9, 2014.

[81] S. Horke, I. Witte, P. Wilgenbus, M. Krüger, D. Strand, and U. Förstermann, "Paraoxonase-2 reduces oxidative stress in vascular cells and decreases endoplasmic reticulum stressinduced caspase activation," Circulation, vol. 115, no. 15, pp. 2055-2064, 2007.

[82] S. Altenhöfer, I. Witte, J. F. Teiber et al., "One enzyme, two functions. PON2 prevents mitochondrial superoxide formation and apoptosis independent from its lactonase activity," The Journal of Biological Chemistry, vol. 285, no. 32, pp. 2439824403, 2010.

[83] M. Fiorani, A. Guidarelli, M. Blasa et al., "Mitochondria accumulate large amounts of quercetin: prevention of mitochondrial damage and release upon oxidation of the extramitochondrial fraction of the flavonoid," Journal of Nutritional Biochemistry, vol. 21, no. 5, pp. 397-404, 2010.

[84] M. Rosenblat, D. Draganov, C. E. Watson, C. L. Bisgaier, B. N. La Du, and M. Aviram, "Mouse macrophage paraoxonase 2 activity is increased whereas cellular paraoxonase 3 activity is decreased under oxidative stress," Arteriosclerosis, Thrombosis, and Vascular Biology, vol. 23, no. 3, pp. 468-474, 2003.

[85] L. G. Costa, J. Garrick, P. J. Roque, and C. Pellacani, "Nutraceuticals in CNS diseases: potential mechanisms of neuroprotection," in Nutraceuticals: Efficacy, Safety, and Toxicity, R. C. Gupta, Ed., Elsevier, New York, NY, USA, 2015.

[86] C. Boesch-Saadatmandi, R. T. Pospissil, A.-C. Graeser et al., "Effect of quercetin on paraoxonase 2 levels in RAW264.7 macrophages and in human monocytes-role of quercetin metabolism," International Journal of Molecular Sciences, vol. 10, no. 9, pp. 4168-4177, 2009.

[87] Y.-F. Chang, Y.-C. Hsu, H.-F. Hung et al., "Quercetin induces oxidative stress and potentiates the apoptotic action of 2methoxyestradiol in human hepatoma cells," Nutrition and Cancer, vol. 61, no. 5, pp. 735-745, 2009.

[88] A. B. Granado-Serrano, M. A. Martín, L. Bravo, L. Goya, and S. Ramos, "Quercetin modulates NF- $\kappa$ B and AP-1/JNK pathways 
to induce cell death in human hepatoma cells," Nutrition and Cancer, vol. 62, no. 3, pp. 390-401, 2010.

[89] P. Galluzzo, C. Martini, P. Bulzomi et al., "Quercetin-induced apoptotic cascade in cancer cells: antioxidant versus estrogen receptor $\alpha$-dependent mechanisms," Molecular Nutrition and Food Research, vol. 53, no. 6, pp. 699-708, 2009.

[90] G. Mariño, F. Madeo, and G. Kroemer, "Autophagy for tissue homeostasis and neuroprotection," Current Opinion in Cell Biology, vol. 23, no. 2, pp. 198-206, 2011.

[91] B. Gabryel, A. Kost, and D. Kasprowska, "Neuronal autophagy in cerebral ischemia-a potential target for neuroprotective strategies?" Pharmacological Reports, vol. 64, no. 1, pp. 1-15, 2012.

[92] S. Giordano, V. Darley-Usmar, and J. Zhang, "Autophagy as an essential cellular antioxidant pathway in neurodegenerative disease," Redox Biology, vol. 2, no. 1, pp. 82-90, 2013.

[93] T. Pan, P. Rawal, Y. Wu, W. Xie, J. Jankovic, and W. Le, "Rapamycin protects against rotenone-induced apoptosis through autophagy induction," Neuroscience, vol. 164, no. 2, pp. 541-551, 2009.

[94] M. Komatsu, S. Waguri, T. Chiba et al., "Loss of autophagy in the central nervous system causes neurodegeneration in mice," Nature, vol. 441, no. 7095, pp. 880-884, 2006.

[95] L. Qu, X. C. Liang, B. Gu, and W. Liu, "Quercetin alleviates high glucose-induced Schwann cell damage by autophagy," Neural Regeneration Research, vol. 9, no. 12, pp. 1195-1203, 2014.

[96] C. Regitz, L. M. Dußling, and U. Wenzel, "Amyloid-beta $\left(\mathrm{A} \beta_{1-42}\right)$-induced paralysis in Caenorhabditis elegans is inhibited by the polyphenol quercetin through activation of protein degradation pathways," Molecular Nutrition \& Food Research, vol. 58, no. 10, pp. 1931-1940, 2014.

[97] W. Dang, “The controversial world of sirtuins," Drug Discovery Today: Technologies, vol. 12, pp. e9-e17, 2014.

[98] L. Leyton, M. Hott, F. Acuña et al., "Nutraceutical activators of AMPK/Sirtl axis inhibit viral production and protect neurons from neurodegenerative events triggered during HSV-1 infection," Virus Research, vol. 205, pp. 63-72, 2015.

[99] S. Skaper, L. Facci, and P. Giusti, "Neuroinflammation, microglia and mast cells in the pathophysiology of neurocognitive disorders: a review," CNS \& Neurological Disorders-Drug Targets, vol. 13, no. 10, pp. 1654-1666, 2015.

[100] B. T. Baune, "Inflammation and neurodegenerative disorders: is there still hope for therapeutic intervention?" Current Opinion in Psychiatry, vol. 28, no. 2, pp. 148-154, 2015.

[101] S. J. Chinta, A. Ganesan, P. Reis-Rodrigues, G. J. Lithgow, and J. K. Andersen, "Anti-inflammatory role of the isoflavone diadzein in lipopolysaccharide-stimulated microglia: implications for Parkinson's disease," Neurotoxicity Research, vol. 23, no. 2, pp. 145-153, 2013.

[102] J.-C. Chen, F.-M. Ho, P.-D. L. Chao et al., "Inhibition of iNOS gene expression by quercetin is mediated by the inhibition of I $\kappa$ B kinase, nuclear factor-kappa B and STAT1, and depends on heme oxygenase-1 induction in mouse BV-2 microglia," European Journal of Pharmacology, vol. 521, no. 1-3, pp. 9-20, 2005.

[103] G. Bureau, F. Longpré, and M.-G. Martinoli, "Resveratrol and quercetin, two natural polyphenols, reduce apoptotic neuronal cell death induced by neuroinflammation," Journal of Neuroscience Research, vol. 86, no. 2, pp. 403-410, 2008.

[104] V. Sharma, M. Mishra, S. Ghosh et al., "Modulation of interleukin-1 $\beta$ mediated inflammatory response in human astrocytes by flavonoids: implications in neuroprotection," Brain Research Bulletin, vol. 73, no. 1-3, pp. 55-63, 2007.

[105] P. Miodini, L. Fioravanti, G. Di Fronzo, and V. Cappelletti, "The two phyto-oestrogens genistein and quercetin exert different effects on oestrogen receptor function," British Journal of Cancer, vol. 80, no. 8, pp. 1150-1155, 1999.

[106] H. van der Woude, M. G. R. ter Veld, N. Jacobs, P. T. van der Saag, A. J. Murk, and I. M. C. M. Rietjens, "The stimulation of cell proliferation by quercetin is mediated by the estrogen receptor," Molecular Nutrition \& Food Research, vol. 49, no. 8, pp. 763-771, 2005.

[107] P. Bulzomi, P. Galluzzo, A. Bolli, S. Leone, F. Acconcia, and M. Marino, "The pro-apoptotic effect of quercetin in cancer cell lines requires ER $\beta$-dependent signals," Journal of Cellular Physiology, vol. 227, no. 5, pp. 1891-1898, 2012.

[108] J. W. Simpkins, K. D. Yi, S.-H. Yang, and J. A. Dykens, "Mitochondrial mechanisms of estrogen neuroprotection," Biochimica et Biophysica Acta (BBA)_General Subjects, vol. 1800, no. 10, pp. 1113-1120, 2010.

[109] I. Azcoitia, M.-A. Arevalo, A. F. De Nicola, and L. M. GarciaSegura, "Neuroprotective actions of estradiol revisited," Trends in Endocrinology and Metabolism, vol. 22, no. 12, pp. 467-473, 2011.

[110] D. Del Rio, L. G. Costa, M. E. J. Lean, and A. Crozier, "Polyphenols and health: what compounds are involved?" Nutrition, Metabolism \& Cardiovascular Diseases, vol. 20, no. 1, pp. 1-6, 2010. 


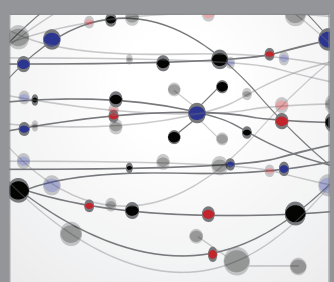

The Scientific World Journal
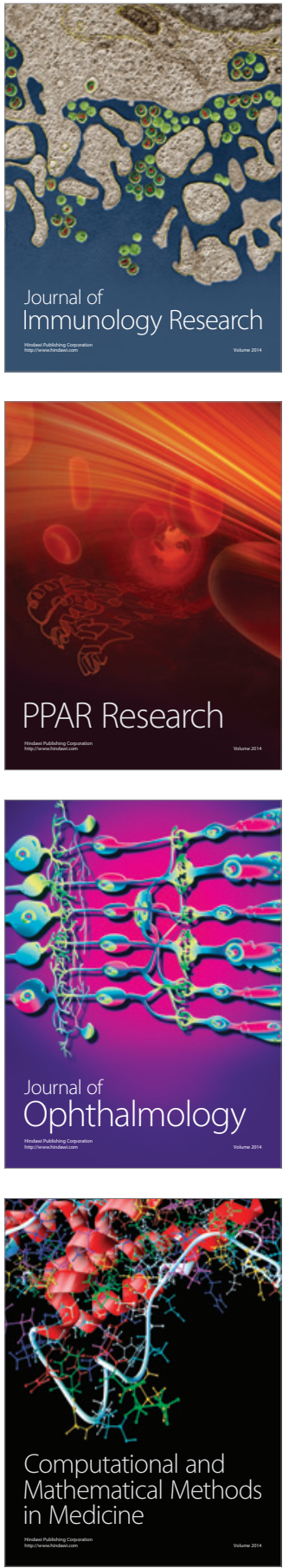

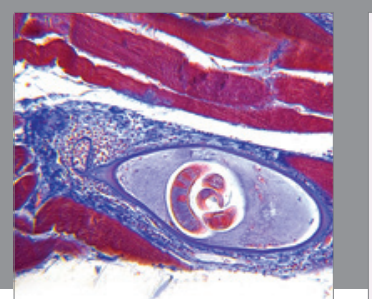

Gastroenterology Research and Practice

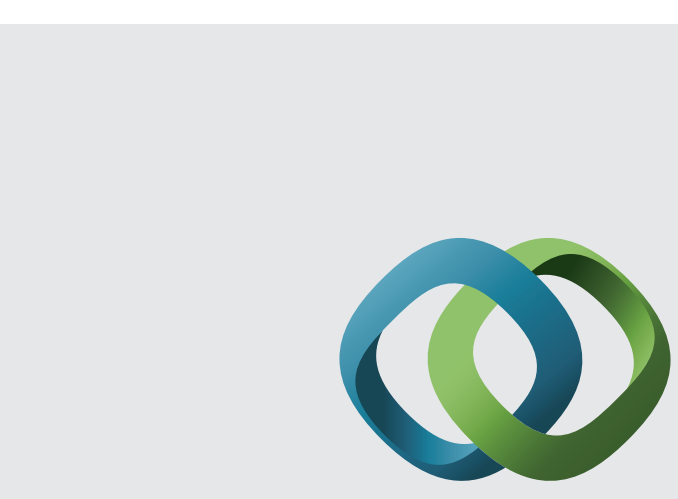

\section{Hindawi}

Submit your manuscripts at

http://www.hindawi.com
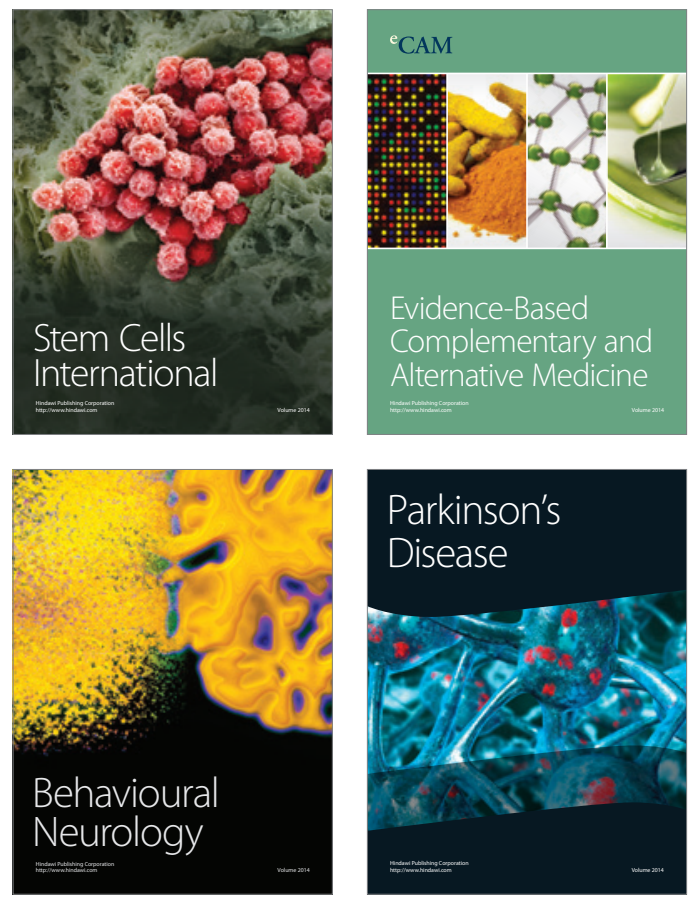
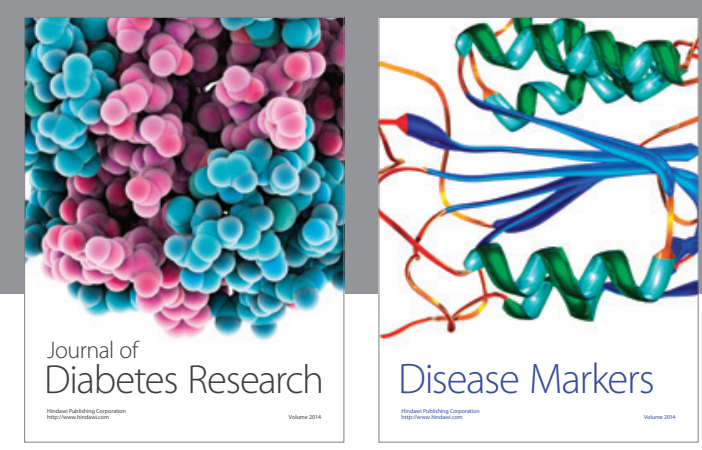

Disease Markers
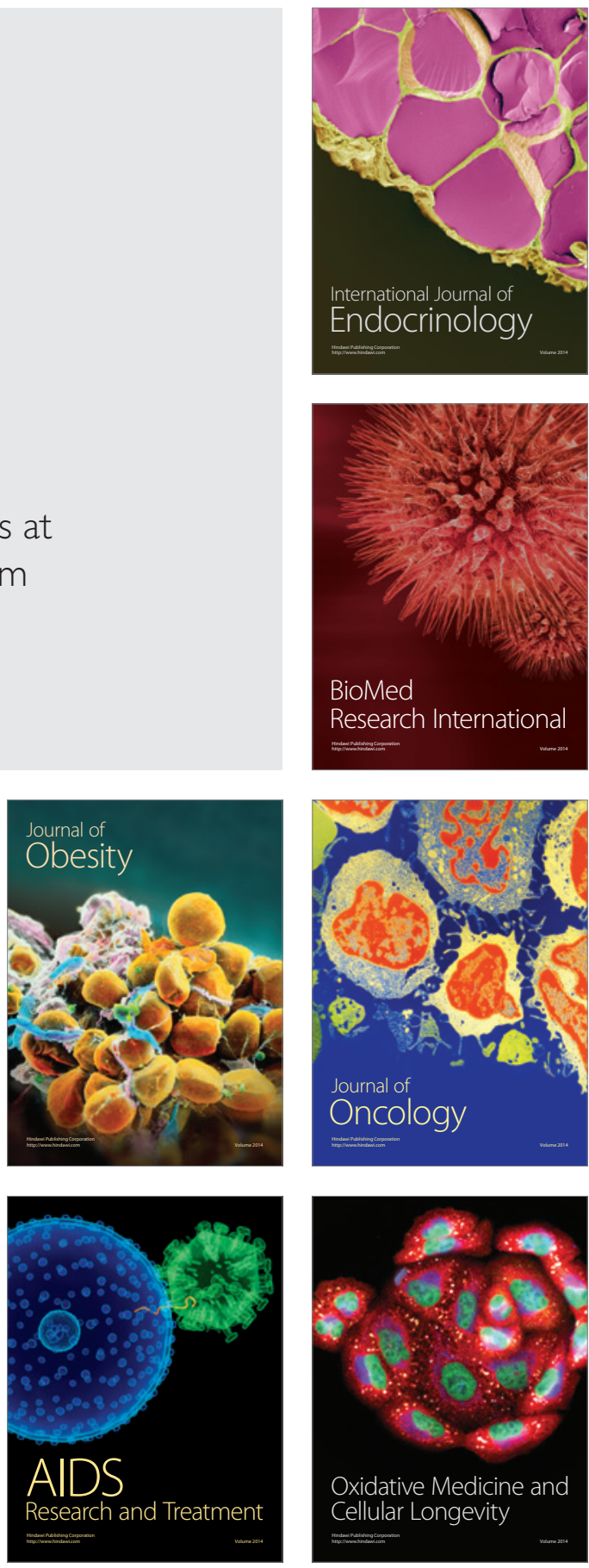